\title{
Identificação de alvos para locação de poços
}

\author{
Aline Isabel de Pádua (aline.geofisica@gmail.com) - PHYGEO/ UnB \\ Daniel Sobreira de Oliveira Buso* (danielbuso.geo@gmail.com) - PHYGEO/ UnB \\ Matheus Rodrigues Cunha (mathrodcunha@gmail.com) - PHYGEO/ UnB \\ Paulo Henrique Praça (phpraca@gmail.com) - PHYGEO/ UnB \\ João Fernando Pezza Andrade (ifernando.geof@gmail.com) - PHYGEO/UnB \\ Amanda Almeida Rocha (amanda7k@gmail.com) - PHYGEO/ UnB \\ Luciano Soares da Cunha (lucianosc@unb.br) - UnB
}

Copyright 2014, SBGf - Sociedade Brasileira de Geofísica

Este texto foi preparado para a apresentação no VI Simpósio Brasileiro de Geofísica, Porto Alegre, 14a 16 de outubro de 2014. Seu conteúdo foi revisado pelo Comite Técnico do VISimBGf, mas não necessariamente representa a opinião da SBGf ou de seus associados. E proibida a reprodução total ou parcial deste material para propósitos comerciais sem prévia autorização da SBGf.

\section{Abstract}

This paper presents results of geophysical surveys carried out in the city of Águas Lindas/GO. The objective of this paper is to detect propitious places for water sources locations through the resistivity geophysical method, moreover, defining better geological structures and hydrological parameters that may help to define the best places for drilling.

\section{Introdução}

Esse trabalho foi desenvolvido em uma área onde será implantado um conjunto habitacional, logo, se torna essencial um sistema de abastecimento de água eficiente para a população local. A captação de água subterrânea é uma eficiente alternativa para região

A água subterrânea, quando presente, ocorre em extensas áreas e de acordo com a demanda exigida, é planejada a locação de mais poços, respeitando a capacidade do aquífero. Os custos de implementação de poços profundos são inferiores aos custos para os sistemas de implementação superficiais, como barragens ou adutoras. Esse tipo de sistema não é dependente de períodos de chuva, não passa por processos de evapotranspiração e não provoca grandes impactos ambientais (Braga, 2007).

A área de estudo está localizada na cidade de Águas Lindas/GO, região que faz parte do entorno de Brasília. O Distrito Federal e a região do entorno situam-se no interior de faixa de dobramento Brasília, entre a posição oriental do Maciço Mediano de Goiás e o Cráton São Francisco (Almeida, 1969), onde são individualizadas quatro sequências de sedimentação, representadas pelos grupos: Canastra, Paranoá, Araxá e Bambuí e que foram dobradas e metamorfizadas no Neoproterozóico, com evolução entre 1000 e 650 Ma, no ciclo Geotectônico Brasiliano.

A região de Águas Lindas está dentro do Grupo Paranoá, constituído por metarritmitos arenosos ou argilosos e quartzitos, na área afloram os metapelitos do Grupo
Araxá, que se sobrepõem ao Grupo Paranoá por meio de uma falha de empurrão de direção NW/SE. A cobertura de solo da região é dendrito-laterítica, com solos de espessura média de 4 a 6 metros e apresenta como principal característica, do ponto de vista geotécnico, alta condutividade hidráulica.

\section{Metodologia/ Problema Investigado}

O método utilizado para localização de alvos geofísicos como áreas potenciais para a locação de poços, foi o da eletrorresistividade, aliada a um anterior conhecimento da geologia local.

Este método tem como base o estudo do potencial elétrico de campos elétricos naturais, existentes na crosta terrestre, bem como dos campos de origem artificial. $\mathrm{O}$ levantamento é realizado a partir de medições do potencial elétrico na superfície e desta forma pode-se determinar no subsolo a existência de corpos minerais e reconhecer estruturas geológicas (Telford et al., 1990).

A resistividade ( $\rho$ ) é o parâmetro utilizado pelo método de eletrorresistividade. O princípio deste método é baseado na passagem de uma corrente contínua I pelo solo, esta é transmitida por um par de eletrodos A e B ligados a um emissor. É medida a diferença de potencial $\Delta \mathrm{V}$ entre dois eletrodos $\mathrm{M}$ e $\mathrm{N}$, e depende da constante $\mathrm{K}$, definida através das dimensões do arranjo do quadrupolo ABMN (Eq. 1):

$$
K=\frac{2 \pi}{\frac{1}{A M}-\frac{1}{B M}-\frac{1}{A N}+\frac{1}{B N}}(\text { Eq. 1) }
$$

Utilizou-se a técnica do caminhamento elétrico, que se baseia na análise e interpretação dos dados a partir do parâmetro de resistividade ou cargabilidade, que investiga variações laterais desses valores.

Nesse Contexto, foi realizada aquisição total de 2085 metros, dispostos em três perfis (AL1, AL2 e AL3) com 550 metros de comprimento cada e espaçamento de 10 metros entre os eletrodos, e mais outros três perfis (AL4, AL5 e AL6) com 385 metros de comprimento cada e espaçamento de 7 metros entre os eletrodos (Figura 01), ambos com o arranjo dipolo-dipolo. 


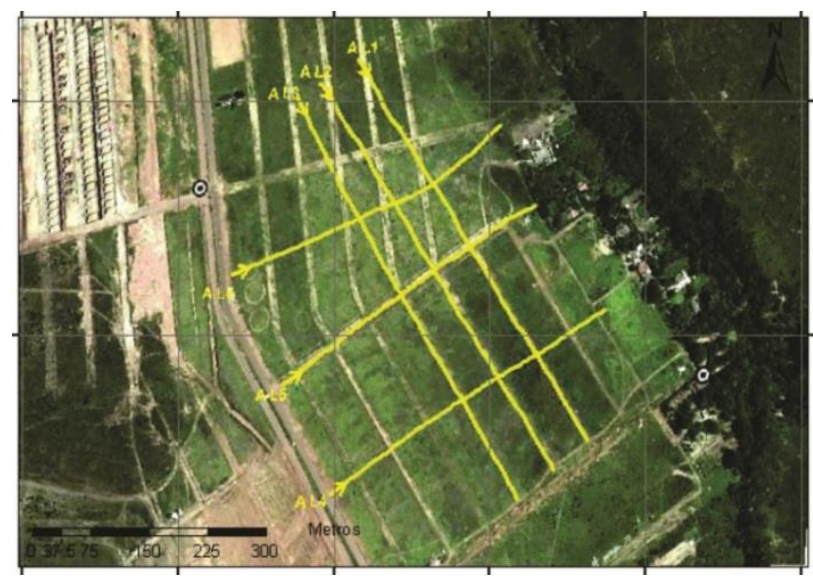

Figura 1 - Disposição das linhas de aquisição.

As aquisições foram realizadas em fevereiro, com o equipamento Super Sting R8 IP com 56 canais (Figura 02).
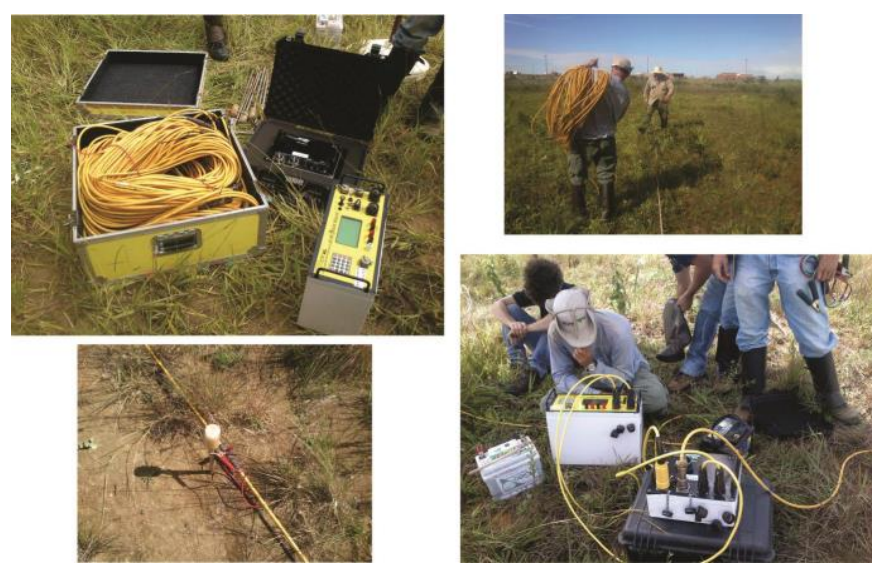

Figura 2 - Mosaico evidencia a aquisição de dados com o equipamento Super Sting R8 IP.

\section{Resultados}

Os resultados de eletrorresistividade apresentados neste trabalho possibilitam a interpretação de zonas com maior potencial para locação de poços.

Os dados de campo foram modelados no software RES2DINV. Durante a modelagem os pontos ruins foram eliminados (Figura 3) e é possível observar na imagem que poucos pontos ruins apareceram nos dados, o que fornece maior segurança de que a aquisição foi adequada e confiável.

Os resultados obtidos na linha AL1 (Figura 4), AL2 (Figura 5) e AL3 (Figura 8) possuem 550 metros de comprimento e apresentaram resultados semelhantes e a profundidade de investigação alcançada foi de $106 \mathrm{~m}$. É possível observar na seção uma zona mais resistiva até os 400 metros (>7000 Ohm.m) e uma zona mais condutiva ( $<145$ Ohm.m) no final do perfil, a partir de uma profundidade de 8 metros.

Os perfis AL4 (Figura 6), AL5 e AL6 (Figura 7) possuem 385 metros de comprimento. No perfil AL4 é possível observar uma grande zona condutiva a partir dos 8 metros de profundidade e na parte superior uma zona com alta resistividade. Já os perfis AL5 e AL6 apresentaram, quase que por completo, valores com alta resistividade.

\section{Discussão e Conclusões}

Após a integração dos resultados do levantamento geofísico, com o conhecimento geológico e dos dados dos poços tubulares existentes, foi possível caracterizar o potencial hidrogeológico da área investigada.

A Figura 8 mostra o perfil AL3 interpretado com destaque para as zonas consideradas com maior e menor potencial hidrogeológico na área.

Os altos valores de resistividade encontrados, principalmente nos perfis AL2 e AL6, podem indicar um aquífero de bom potencial hídrico subterrâneo. Tendo em vista a interpretação dos perfis, a região foi subdividida em duas zonas de potencial hidrogeológico, sendo a região centro-norte da área como a de maior potencial quando comparada a porção centro-sul (Figura 9). Essas áreas foram delimitadas em relação à capacidade de armazenar água levando em consideração a geologia local.

A partir dessa caracterização são indicados três pontos para construção de poços tubulares profundos na zona centro-norte de maior potencial.

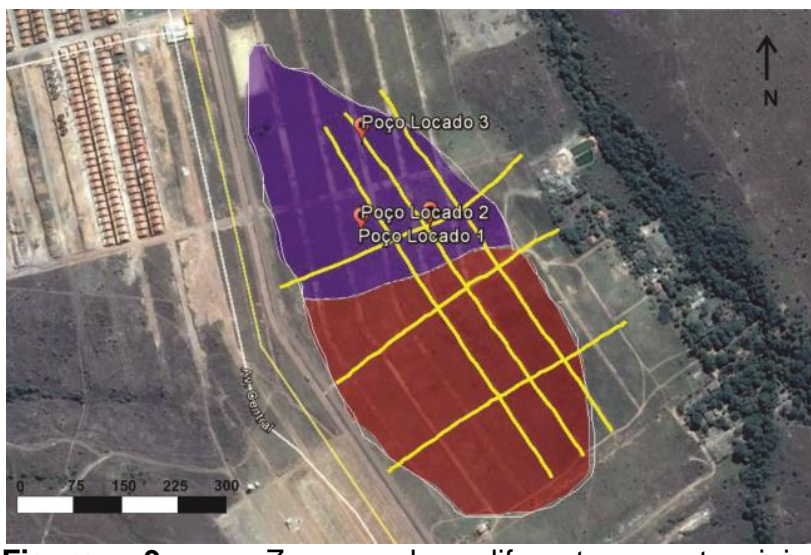

Figura 9 - Zonas de diferentes potenciais hidrogeológicos, a região em azul se apresenta como zona de maior potencial quando comparada a zona delimitada em vermelho, são evidenciados os locais indicados para a locação dos poços.

\section{Agradecimentos}

Ao Laboratório de Geofísica Aplicada (LGA/IG/UnB) pela disponibilização dos equipamentos geofísicos.

A Empresa CIEGE pela autorização da publicação do trabalho.

\section{Referências}

ALMEIDA, F.F.M. 1969 Diferenciação tectônica da plataforma brasileira. In: CONGR. BRÁS. GEOL., 23. Salvador, 1969. Anais... Salvador, SBG. p.29-46. 
TELFORD WM, GELDART LP e SHERIFF RE. 1990. Applied geophysics. Segunda Edição. Cambridge: Cambridge University Press, 770 p.

BRAGA. ACO.2007. Métodos Geoelétricos aplicados nos Estudos de Contaminação de águas Subterrâneas. UNESP. Rio Claro
PETCON. Elaboração de Estudo de Impacto Ambiental, respectivo Relatório de Impacto Ambiental (EIA-RIMA) e Plano Básico Ambiental (PBA) para o Licenciamento Ambiental das Obras de Adequação (Duplicação e Ruas Laterais) da BR070/GO, Perímetro de Águas Lindas. DNIT 2006.

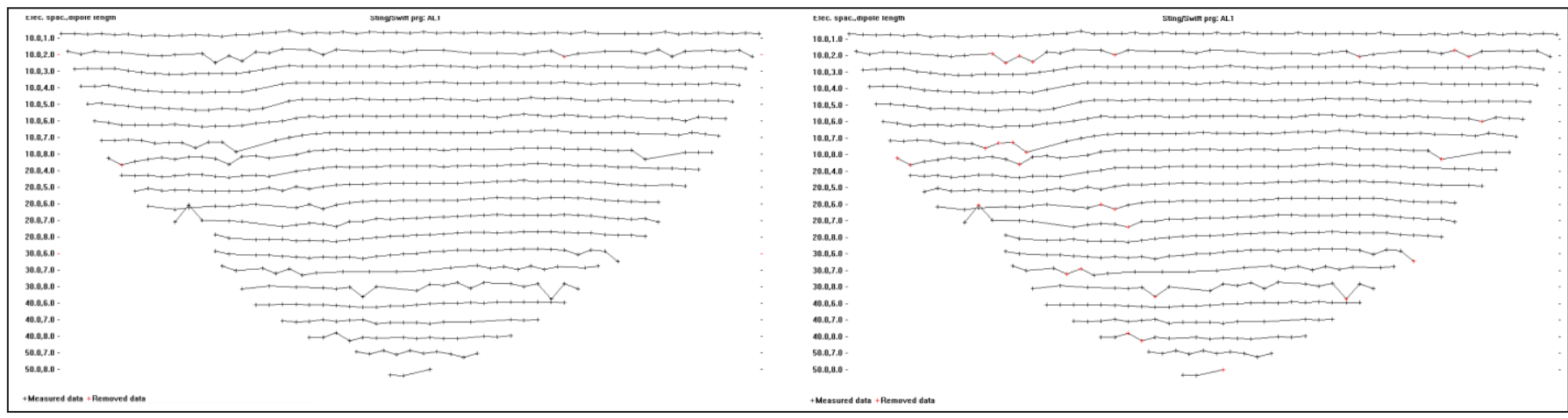

Figura 3 - Imagem dos pontos ruins do perfil AL1 e ao lado os pontos que serão eliminados marcados em vermelho.

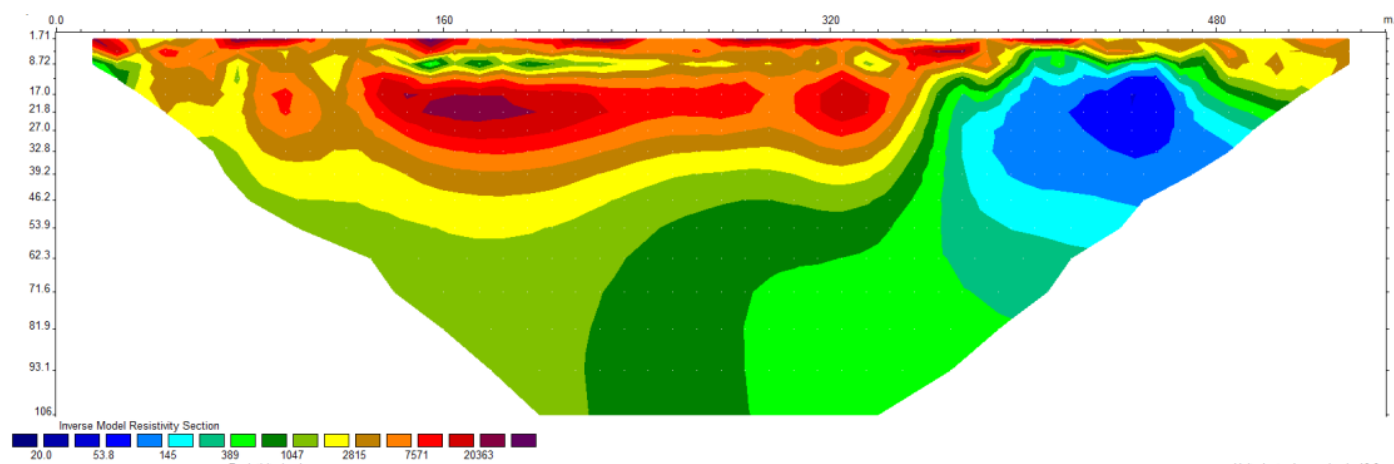

Figura 4 - Perfil obtido na linha AL1.

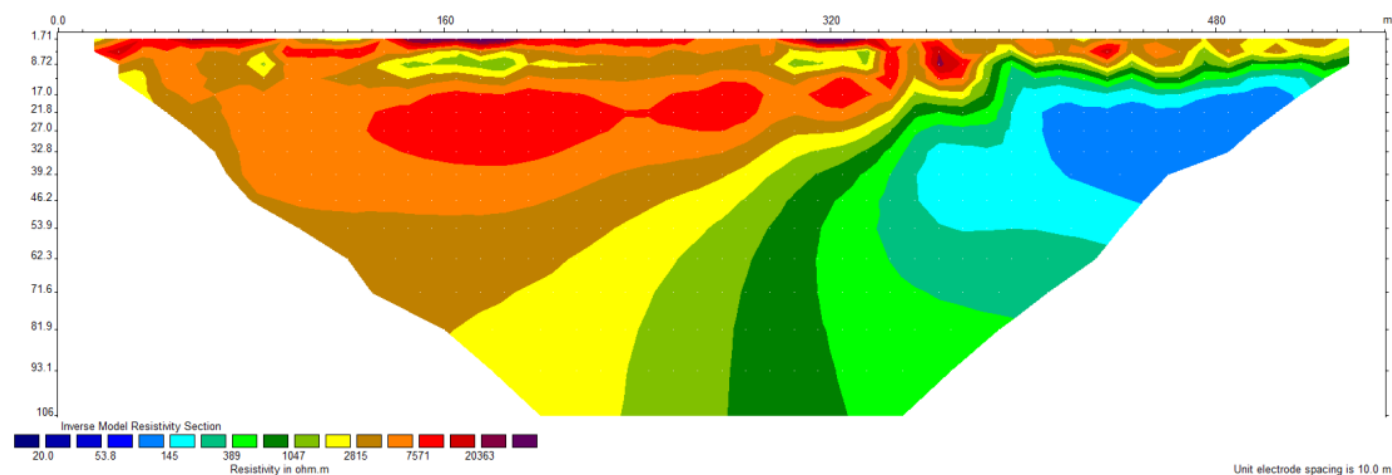

Figura 5 - Perfil obtido na linha AL2. 


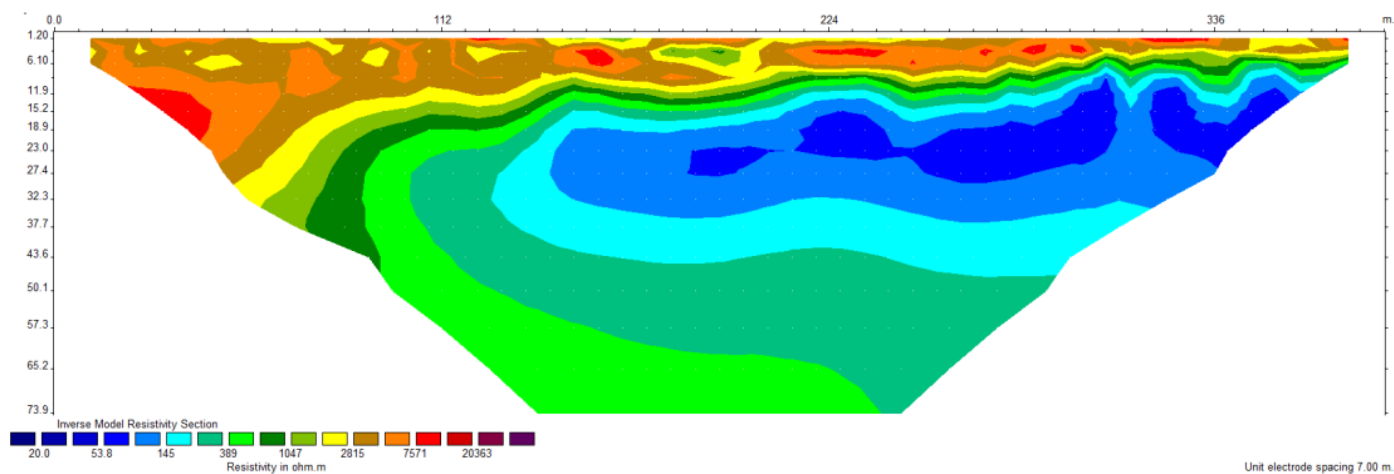

Figura 6 - Perfil obtido na linha AL4.

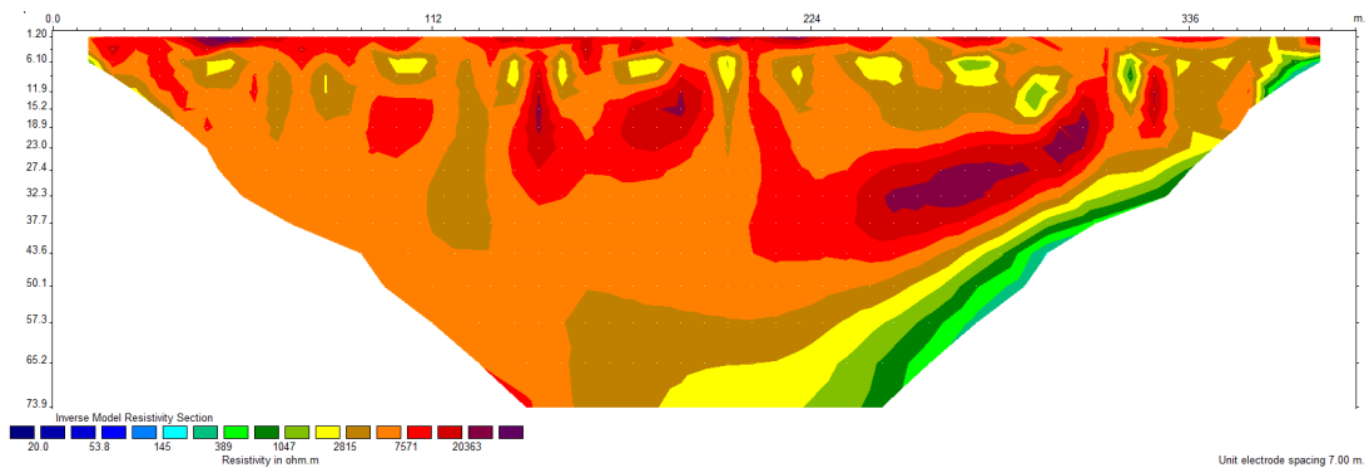

Figura 7 - Perfil obtido na linha AL6.

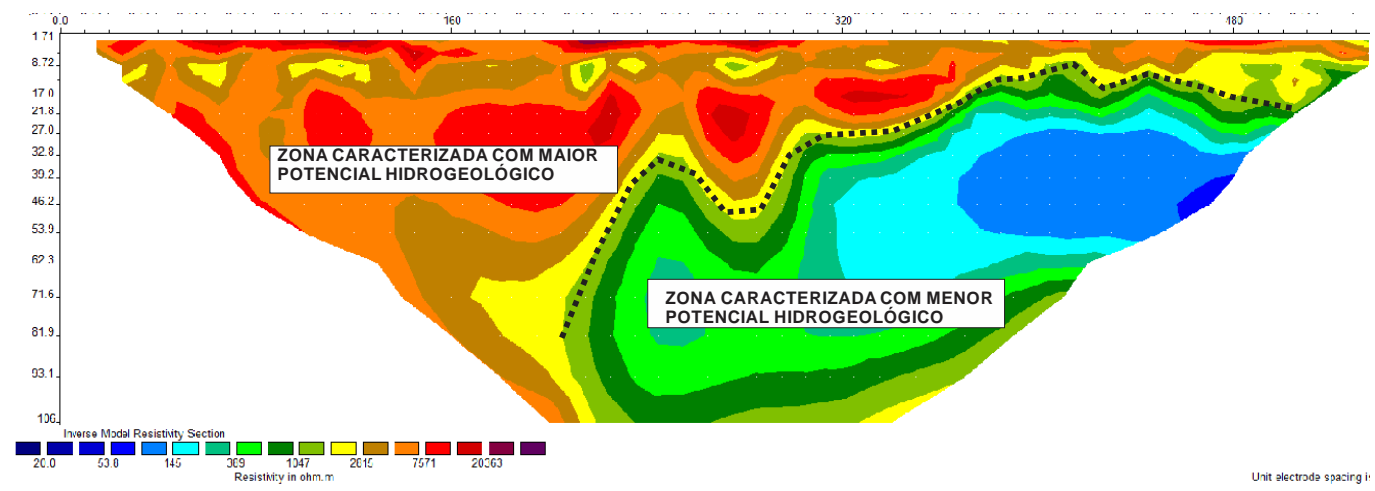

Figura 8 - Perfil com interpretação obtido na linha AL3. 